\title{
Clustering Fasilitas Kesehatan Berdasarkan Kecamatan Di Karawang Dengan Algoritma K-Means
}

\author{
Bagus Muhammad Islami ${ }^{1,}$, Cepy Sukmayadi ${ }^{1}$, Tesa Nur Padilah ${ }^{1}$ \\ $1^{*}, 1$ IImu Komputer; Universitas Singaperbangsa Karawang; JI. HS. Ronggo Waluyo, Teluk \\ Jambe Timur, Karawang, Jawa Barat, Indonesia - 41361; telp/fax: 0812-95094228; e-mail: \\ bagus.muhammad17065@student.unsika.ac.id, cepy.sukmayadi17009@student.unsika.ac.id, \\ tesa.nurpadilah@staff.unsika.ac.id \\ * Korespondensi: e-mail: bagus.muhammad17065@student.unsika.ac.id
}

Diterima: 20 Mei 2021; Review: 14 Juni 2021; Disetujui: 25 Juni 2021

Cara sitasi: Islami BM, Sukmayadi C, Padilah TS. 2021. Clustering Fasilitas Kesehatan Berdasarkan Kecamatan Di Karawang Dengan Algoritma K-Means. Bina Insani ICT Journal. Vol. 8 (1): 83-92.

\begin{abstract}
Abstrak: Masalah kesehatan yang ada di dalam masyarakat terutama di negara- negara berkembang seperti Indonesia dipengaruhi oleh dua faktor yaitu aspek fisik dan aspek non fisik. Berdasarkan data yang diperoleh dari karawangkab.bps.go.id data dibagi menjadi 3 cluster yaitu sedikit, sedang dan terbanyak. Algoritma yang digunakan adalah K-Means cluster yang diimplementsikan menggunakan Microsoft Excel dan Rapidminer Studio. Hasil pengolahan data fasilitas kesehatan di karawang menghasilkan 3 cluster dengan cluster 1 yang mempunyai fasilitas kesehatan sedikit sebanyak 23 kecamatan, cluster 2 yang mempunyai fasilitas kesehatan sedang sebanyak 5 kecamatan dan cluster 3 yang mempunyai fasilitas kesehatan terbanyak terdapat 2 kecamatan. Kinerja yang dihasilkan dari algoritma K-means menghasilkan nilai Davies Boildin Index sebesar 0,109.
\end{abstract}

Kata kunci: clustering, data mining, fasilitas kesehatan, K-Means.

Abstract: Health problems that exist in society, especially in developing countries like Indonesia, are built by two factors, namely physical and non-physical aspects. Based on data obtained from karawangkab.bps.go.id the data is divided into 3 clusters, namely the least, medium and the most. The algorithm used is the K-Means cluster which is implemented using Microsoft Excel and Rapidminer Studio. The results of data processing of health facilities in Karawang produce 3 clusters with cluster 1 which has 23 sub-districts of health facilities, cluster 2 which has medium health facilities as many as 5 districts and cluster 3 which has the most health facilities in 2 districts. The performance resulting from the $K$-means algorithm results in a Davies Boildin Index value of 0.109.

Keywords: clustering, data mining, health facilities, K-Means.

\section{Pendahuluan}

Masalah kesehatan yang ada di dalam masyarakat terutama di negara- negara berkembang seperti Indonesia dipengaruh oleh dua faktor yaitu aspek fisik dan aspek non fisik. Aspek fisik seperti sarana kesehatan dan pengobatan penyakit, sedangkan yang kedua adalah aspek non fisik yang menyangkut masalah kesehatan seperti perilaku Manusia dalam bentuk pengetahuan, sikap dan tindakan [1]. Pelayanan kesehatan merupakan hak dasar masyarakat yang harus dipenuhi dalam pembangunan kesehatan [2]. Pembangunan kesehatan diselenggarakan untuk meningkatkan kesadaran, kemauan, dan kemampuan hidup sehat bagi setiap orang agar terwujud derajat kesehatan masyarakat yang setinggi-tingginya.

Fasilitas kesehatan yang ada di Indonesia sangat perlu diperhatikan oleh pemerintah khususnya di kecamatan yang ada di Karawang ini masih tergolong kurang. Contohnya seperti 
puskesmas, rumah sakit, klinik, maupun tempat pengobatan lainnya. Sarana kesehatan yang tidak tercukupi di beberapa Kecamatan yang ada di Karawang akan membuat masyarakat di Kecamatan tersebut kesulitan untuk hidup sehat dan mengobati penyakitnya. Seperti contoh jika ada ibu hamil yang ingin bersalin akan kesulitan apabila sarananya tidak memadai. Oleh sebab itu, pemerintah diharapkan dapat memperbaiki kondisi sarana kesehatan yang kurang di Kabupaten Karawang. Penelitian ini bertujuan untuk melakukan pengelompokkan terhadap Kecamatan yang memiliki sarana kesehatan dengan cepat dan efektif.

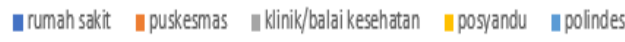

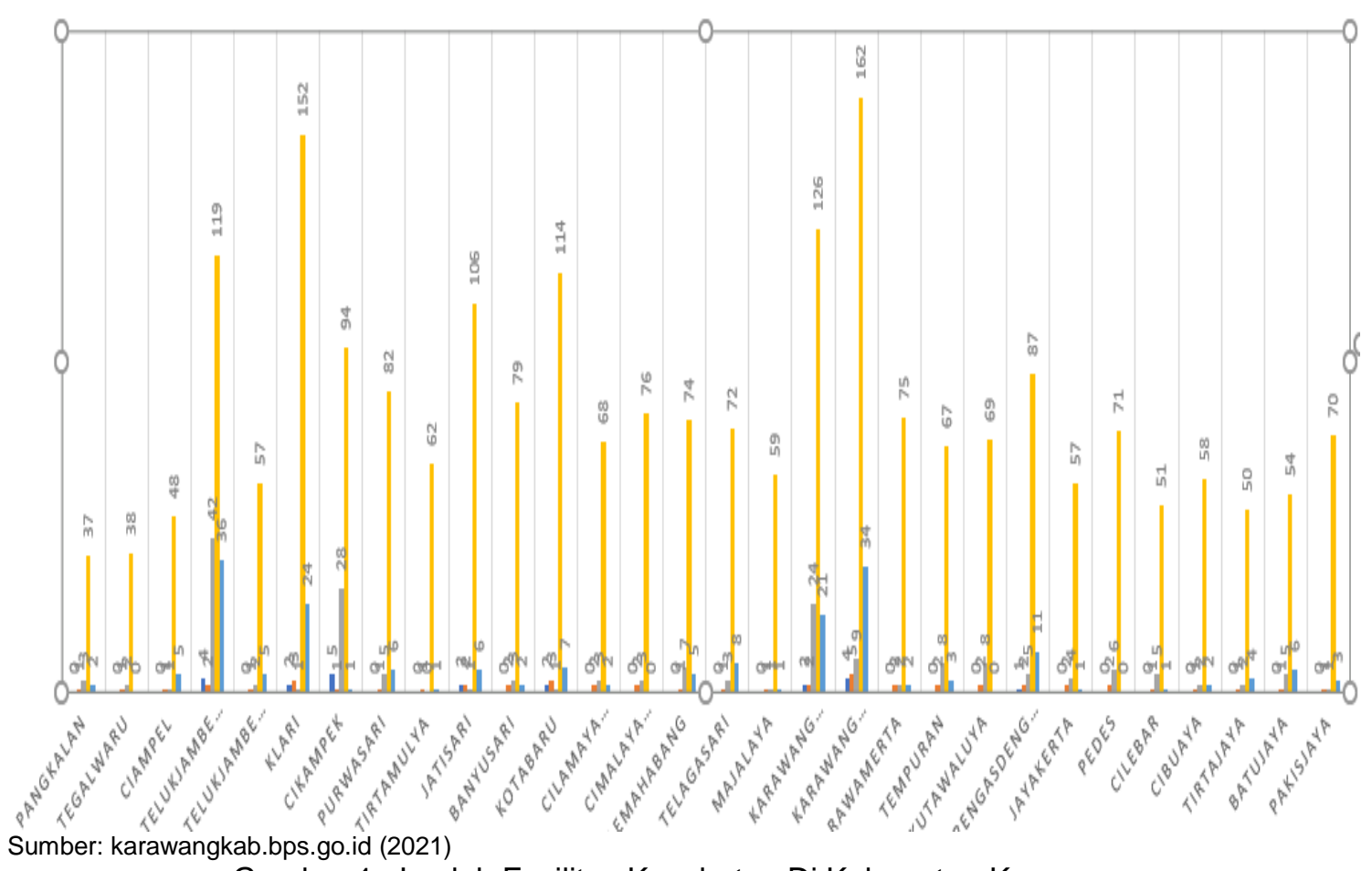

Gambar 1. Jumlah Fasilitas Kesehatan Di Kabupaten Karawang

Clustering merupakan sebuah metode pengelompokan suatu obyek kedalam sejumlah kelompok (cluster) yang sesuai. Prinsip dari clustering adalah memaksimalkan kesamaan antar anggota satu cluster dan meminimumkan kesamaan antar anggota cluster yang berbeda. Analisis cluster berfungsi sebagai pemisah obyek kedalam beberapa kelompok yang memiliki perbedaan karakteristik antar kelompok. K-Means merupakan teknik pengelompokan hard partition yang efisien dalam mengelompokan data besar, namun terbatas hanya pada data numerik [3].

\section{Metode Penelitian}

Penelitian ini menggunakan dataset fasilitas kesehatan di kabupaten karawang. Dataset tersebut kemudian dikelompokan menggunakan algoritma K-Means. Pengelompokan Fasilitas Kesehatan dengan algoritma k-means ini dilakukan dengan beberapa tahapan, yaitu: a) Pengumpulan data, tahapan ini dilakukan untuk mencari data-data yang akan digunakan dalam penelitian terkait clustering fasilitas Kesehatan data diambil dari situs resmi Badan Pusat Statistik Karawang (karawangkab.bps.go.id), b) Pengolahan dataset menggunakan microsoft excel, merupakan tahap pengolahan data menggunakan algoritma K-Means untuk mendapatkan kelompok data fasilitas kesehatan. Aplikasi yang digunakan tahapan ini adalah microsoft excel, c) Implementasi K-Means cluster dengan Rapidminer, sebagai bahan perbandingan pengolahan data yang sudah dilakukan menggunakan microsoft excel juga dilakukan pengolahan data kembali menggunakan aplikasi rapidminer studio, d) Analisa hasil pengolahan data, berdasarkan hasil pengolahan data yang telah dilakukan menggunakan microsoft excel dan rapidminer studio, kemudian data tersebut dianalisa dalam bentuk cluster model dan performance vector atas clustering fasilitas kesehatan. 


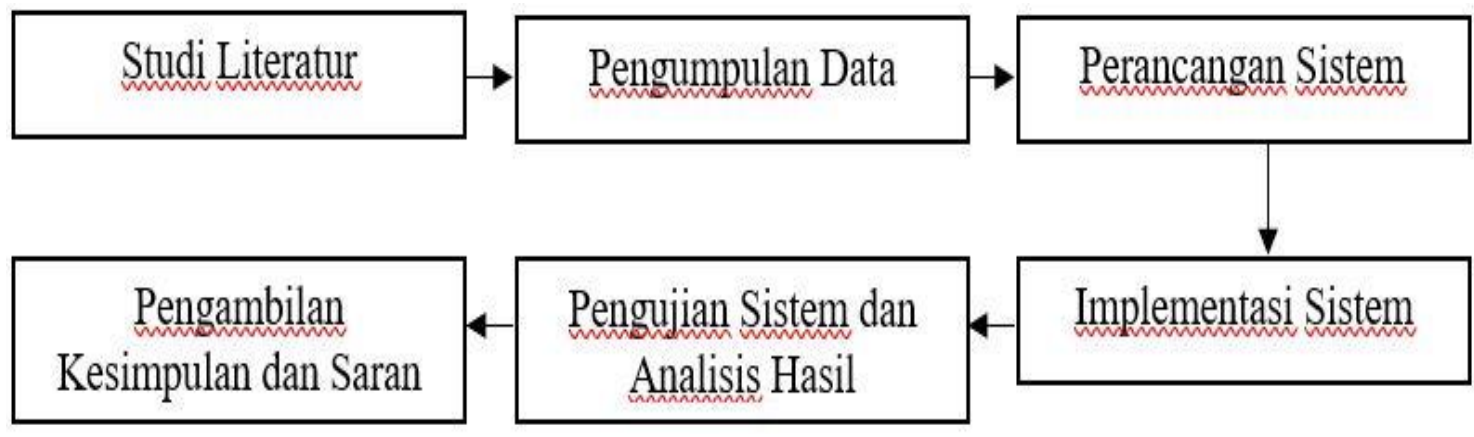

Sumber: Hasil Penelitian (2021)

Gambar 2. Alur penelitian

\section{Data Mining}

Kegiatan mencari knowledge terpendam dari himpunan data yang amat banyak adalah definisi dari data mining [8]. Output atau hasil dari proses data mining bisa dijadikan bahan untuk menentukan langkah di waktu yang akan datang [9]. Berdasarkan tugasnya data mining terbagi menjadi 6 metode yaitu description, estimation, prediction, classification, clustering, serta association [9]. Data mining berfungsi untuk menambang pengetahuan berharga yang tersembunyi di dalam sebuah data [10].

\section{Clustering}

Clustering merupakan salah satu teknik data mining yang digunakan untuk mendapatkan kelompok-kelompok dari objek objek yang mempunyai karakteristik yang umum di data yang cukup besar [4]. Cluster berbeda dari klasifikasi karena cluster tidak memiliki variabel target. Tujuan cluster bukan untuk mengklasifikasikan, memperkirakan, atau memprediksi nilai variabel taget [1].

\section{K-Means Clustering}

K-means merupakan suatu algoritma pengklasteran yang cukup sederhana yang mempartisi dataset kedalam beberapa klaster $\mathrm{k}$ [5]. Tahapan yang dilakukan dalam algoritma KMeans adalah sebagai berikut [6]: Tentukan jumlah cluster dan tetapkan secara acak pusat cluster. Hitung jarak data dengan pusat cluster.

$d(x, y)=\sqrt{\sum_{i=0}^{n}\left(x_{i}-y_{i}\right)^{2}}$

Kelompokan data ke dalam cluster dengan jarak terdekat. Perbarui nilai pusat cluster.

$C_{k}=\left(\frac{1}{n_{k}}\right) \sum d_{i}$

Ulangi langkah 3 dan 5 hingga data pada tiap cluster tidak berubah.

\section{Davies-Bouldin Index (DBI)}

DBI Merupakan salah satu uji validitas internal pada metode. Pengelompokan basis partisi berdasarkan jumlah dari kedekatan data terhadap centroid dari cluster yang diikutinya dan diantara dua cluster diukur dengan kedekatan dua centroid cluster. DBI bertujuan untuk memaksimalkan jarak inter-cluster, Dengan menggunakan Davies Bouldin Index suatu cluster akan dianggap memiliki skema clustering yang optimal [11] semakin kecil nilai DBI maka semakin baik pula hasil dari cluster tersebut.

\section{Min-Max Normalization}

Salah satu dari banyak metode pada normalisasi data adalah metode min-max normalization. metode ini mengubah nilai pada dataset kedalam skala atau range yang lebih kecil yang bernilai 0 sampai dengan 1 [12]. Berikut merupakan persamaan pada min-max normalization. 


$$
d=\frac{d-\min (p)}{\max (p)-\min (p)}
$$

\section{Hasil dan Pembahasan}

Dataset yang digunakan pada penelitian ini adalah data fasilitas kesehatan di Kabupaten Karawang. Data diambil dari situs resmi Badan Pusat Statistik Kabupaten Karawang (karawangkab.bps.go.id). Data tersebut terdiri dari 30 kecamatan dengan 5 variabel. Berikut data dari BPS Karawang yang ditampilkan pada tabel 1.

Tabel 1. Data Fasilitas Kesehatan yang ada di Kabupaten Karawang

\begin{tabular}{|c|c|c|c|c|c|c|c|}
\hline No & Kabupaten & Rumah Sakit & Puskesmas & Balai Kesehatan & Posyandu & Polindes & Apotek \\
\hline 1 & Pangkalan & 0 & 1 & 3 & 37 & 2 & 4 \\
\hline 2 & Tegalwaru & 0 & 1 & 2 & 38 & 0 & 1 \\
\hline 3 & Ciampel & 0 & 1 & 1 & 48 & 5 & 3 \\
\hline 4 & Telukjambe Timur & 4 & 2 & 42 & 119 & 36 & 8 \\
\hline 5 & Telukjambe Barat & 0 & 1 & 2 & 57 & 5 & 3 \\
\hline 6 & Klari & 2 & 3 & 1 & 152 & 24 & 9 \\
\hline 7 & Cikampek & 5 & 1 & 28 & 94 & 1 & 6 \\
\hline 8 & Purwasari & 0 & 1 & 5 & 82 & 6 & 4 \\
\hline 9 & Tirtamulya & 0 & 1 & 0 & 62 & 1 & 2 \\
\hline 10 & Jatisari & 2 & 2 & 1 & 106 & 6 & 3 \\
\hline 11 & Banyusari & 0 & 2 & 3 & 79 & 2 & 3 \\
\hline 12 & Kotabaru & 2 & 3 & 1 & 114 & 7 & 8 \\
\hline 13 & Cilamaya Wetan & 0 & 2 & 3 & 68 & 2 & 9 \\
\hline 14 & Cimalaya Kulon & 0 & 2 & 3 & 76 & 0 & 5 \\
\hline 15 & Lemahabang & 0 & 1 & 7 & 74 & 5 & 6 \\
\hline 16 & Telagasari & 0 & 1 & 3 & 72 & 8 & 6 \\
\hline 17 & Majalaya & 0 & 1 & 1 & 59 & 1 & 2 \\
\hline 18 & Karawang Timur & 2 & 2 & 24 & 126 & 21 & 7 \\
\hline 19 & Karawang Barat & 4 & 5 & 9 & 162 & 34 & 6 \\
\hline 20 & Rawamerta & 0 & 2 & 2 & 75 & 2 & 3 \\
\hline 21 & Tempuran & 0 & 2 & 8 & 67 & 3 & 6 \\
\hline 22 & Kutawaluya & 0 & 2 & 8 & 69 & 0 & 0 \\
\hline 23 & Rengasdengklok & 1 & 2 & 5 & 87 & 11 & 5 \\
\hline 24 & Jayakerta & 0 & 2 & 4 & 57 & 1 & 1 \\
\hline 25 & Pedes & 0 & 2 & 6 & 71 & 0 & 4 \\
\hline 26 & Cilebar & 0 & 1 & 5 & 51 & 1 & 2 \\
\hline 27 & Cibuaya & 0 & 1 & 2 & 58 & 2 & 2 \\
\hline 28 & Tirtajaya & 0 & 1 & 2 & 50 & 4 & 3 \\
\hline 29 & Batujaya & 0 & 1 & 5 & 54 & 6 & 3 \\
\hline 30 & Pakisjaya & 0 & 1 & 1 & 70 & 3 & 1 \\
\hline
\end{tabular}

Sumber: karawangkab.bps.go.id (2021)

\section{Pengolahan Dataset}

Dataset yang telah didapatkan kemudian dilakukan pengolahan untuk dikelompokkan datanya. Clustering data ini menggunakan algoritma K-Means. Proses pengolahan dataset menggunakan Microsoft Excel untuk mendapatkan hasil cluster dilakukan dengan dua kali perulangan atau iterasi, karena pada iterasi kedua hasil clustering data sama dengan hasil iterasi pertama dengan: 1) Menentukan jumlah cluster, jumlah cluster yang digunakan pada penelitian ini berjumlah 3 cluster yang terdiri dari cluster 1 (C1) merupakan kecamatan dengan fasilitas kesehatan sedikit, cluster 2 (C2) merupakan kecamatan dengan fasilitas sedang dan cluster 3 (C3) merupakan kecamatan dengan fasilitas kesehatan terbanyak. Pusat cluster iterasi pertama meliputi: a) Cluster 1 (sedikit) yang terdiri dari: Rumah Sakit=0, Puskesmas=1, Balai Kesehatan $=1$, Posyandu=48, Polindes $=5$, dan Apotek=3, b) Cluster 2 (sedang) yang terdiri dari: Rumah Sakit=2, Puskesmas=2, Balai Kesehatan=24, Posyandu=126, Polindes=21, dan Apotek=7, dan c) Cluster 3 (banyak) yang terdiri dari: Rumah Sakit=4, Puskesmas=5, Balai Kesehatan=9, Posyandu=162, Polindes $=34$, dan Apotek=6; 2) Menghitung jarak setiap data ke pusat cluster. Jarak setiap data ke pusat cluster ditentukan dengan rumus Euclidian Distance dijelaskan pada tabel 2 .

Tabel 2. Jarak Data ke Pusat Cluster Iterasi Pertama

\begin{tabular}{clcccc}
\hline No & Kabupaten & C1 & C2 & C3 & Jarak Terdekat \\
\hline 1 & Pangkalan & 135 & 8735 & 16709 & 135 \\
\hline 2 & Tegalwaru & 130 & 8708 & 16626 & 130 \\
\hline 3 & Ciampel & 0 & 6888 & 13930 & 0 \\
\hline
\end{tabular}


BINA INSANI ICT JOURNAL ISSN: 2355-3421 (Print) ISSN: 2527-9777 (Online); 83 - 92

\begin{tabular}{clcccc}
\hline No & \multicolumn{1}{c}{ Kabupaten } & C1 & C2 & C3 & Jarak Terdekat \\
\hline 4 & Telukjambe Timur & 7713 & 601 & 2955 & 601 \\
\hline 5 & Telukjambe Barat & 82 & 5520 & 11944 & 82 \\
\hline 6 & Klari & 11219 & 1219 & 279 & 279 \\
\hline 7 & Cikampek & 2875 & 1445 & 6091 & 1445 \\
\hline 8 & Purwasari & 1174 & 2534 & 7224 & 1174 \\
\hline 9 & Tirtamulya & 214 & 5100 & 11206 & 214 \\
\hline 10 & Jatisari & 3368 & 1170 & 4004 & 1170 \\
\hline 11 & Banyusari & 975 & 3029 & 7971 & 975 \\
\hline 12 & Kotabaru & 4391 & 871 & 3107 & 871 \\
\hline 13 & Cilamaya Wetan & 450 & 4172 & 9918 & 450 \\
\hline 14 & Cimalaya Kulon & 818 & 3388 & 8602 & 818 \\
\hline 15 & Lemahabang & 721 & 3253 & 8609 & 721 \\
\hline 16 & Telagasari & 598 & 3530 & 8832 & 598 \\
\hline 17 & Majalaya & 138 & 5446 & 11798 & 138 \\
\hline 18 & Karawang Timur & 6888 & 0 & 1702 & 0 \\
\hline 19 & Karawang Barat & 13930 & 1702 & 0 & 0 \\
\hline 20 & Rawamerta & 740 & 3464 & 8664 & 740 \\
\hline 21 & Tempuran & 424 & 4064 & 10000 & 424 \\
\hline 22 & Kutawaluya & 525 & 3997 & 9855 & 525 \\
\hline 23 & Rengasdengklok & 1579 & 1987 & 6183 & 1579 \\
\hline 24 & Jayakerta & 111 & 5599 & 12177 & 111 \\
\hline 25 & Pedes & 581 & 3801 & 9463 & 581 \\
\hline 26 & Cilebar & 42 & 6414 & 13462 & 42 \\
\hline 27 & Cibuaya & 111 & 5497 & 11925 & 111 \\
\hline 28 & Tirtajaya & 6 & 6568 & 13522 & 6 \\
\hline 29 & Batujaya & 53 & 5789 & 12493 & 53 \\
\hline 30 & Pakisjaya & 492 & 4028 & 9534 & 492 \\
\hline
\end{tabular}

Sumber: Hasil Penelitian (2021)

3) Pengelompokan data ke dalam cluster, data yang mempunyai jarak terdekat akan masuk kedalam cluster tersebut yang dijelaskan pada tabel 3.

Tabel 3. Pengelompokan Data Iterasi Pertama

\begin{tabular}{|c|c|c|c|c|}
\hline No & Kabupaten & C1 & C2 & C3 \\
\hline 1 & Pangkalan & $\mathrm{X}$ & & \\
\hline 2 & Tegalwaru & $\mathrm{X}$ & & \\
\hline 3 & Ciampel & $\mathrm{X}$ & & \\
\hline 4 & Telukjambe Timur & & $X$ & \\
\hline 5 & Telukjambe Barat & $\mathrm{X}$ & & \\
\hline 6 & Klari & & & $\mathrm{X}$ \\
\hline 7 & Cikampek & & $\mathrm{X}$ & \\
\hline 8 & Purwasari & $\mathrm{X}$ & & \\
\hline 9 & Tirtamulya & $\mathrm{X}$ & & \\
\hline 10 & Jatisari & & $\mathrm{X}$ & \\
\hline 11 & Banyusari & $\mathrm{X}$ & & \\
\hline 12 & Kotabaru & & $X$ & \\
\hline 13 & Cilamaya Wetan & $X$ & & \\
\hline 14 & Cimalaya Kulon & $\mathrm{X}$ & & \\
\hline 15 & Lemahabang & $X$ & & \\
\hline 16 & Telagasari & $\mathrm{X}$ & & \\
\hline 17 & Majalaya & $\mathrm{X}$ & & \\
\hline 18 & Karawang Timur & & $X$ & \\
\hline 19 & Karawang Barat & & & $\mathrm{X}$ \\
\hline 20 & Rawamerta & $\mathrm{X}$ & & \\
\hline 21 & Tempuran & $X$ & & \\
\hline 22 & Kutawaluya & $\mathrm{X}$ & & \\
\hline 23 & Rengasdengklok & $X$ & & \\
\hline 24 & Jayakerta & $\mathrm{X}$ & & \\
\hline 25 & Pedes & $\mathrm{X}$ & & \\
\hline 26 & Cilebar & $\mathrm{X}$ & & \\
\hline 27 & Cibuaya & $\mathrm{X}$ & & \\
\hline 28 & Tirtajaya & $X$ & & \\
\hline 29 & Batujaya & $\mathrm{X}$ & & \\
\hline 30 & Pakisjaya & $\mathrm{X}$ & & \\
\hline
\end{tabular}

Sumber: Hasil Penelitian (2021) 
4) Hitung pusat cluster yang baru, hasil pengelompokan iterasi pertama kemudian dihitung ratarata dari setiap cluster pada masing-masing variabel. Hasilnya dijadikan pusat cluster pada iterasi kedua.

Iterasi Kedua: 1) Menentukan jumlah cluster, hasil perhitungan pusat cluster yang baru pada iterasi pertama dijadikan sebagai pusat cluster pada iterasi kedua. Pusat cluster iterasi kedua meliputi: a) Cluster 1 (sedikit) yang terdiri dari: Rumah Sakit $=0,043$, Puskesmas $=1,391$, Balai Kesehatan=3,522, Posyandu=63,522, Polindes=3,043, dan Apotek=3,391, b) Cluster 2 (sedang) yang terdiri dari: Rumah Sakit=3, Puskesmas=2, Balai Kesehatan=19,2, Posyandu=111,8, Polindes=14,2, dan Apotek=6,4, dan c) Cluster 3 (banyak) yang terdiri dari: Rumah Sakit=3, Puskesmas $=4$, Balai Kesehatan $=5$, Posyandu $=157$, Polindes $=29$, dan Apotek=7,5; 2) Menghitung jumlah setiap data ke pusat cluster, jarak setiap data ke pusat cluster ditentukan dengan rumus Euclidian Distance.

Tabel 4. Jarak Data ke Pusat Cluster Iterasi Kedua

\begin{tabular}{clcccc}
\hline No & \multicolumn{1}{c}{ Kabupaten } & $\mathbf{C 1}$ & $\mathbf{C 2}$ & $\mathbf{C 3}$ & Jarak Terdekat \\
\hline 1 & Pangkalan & 705,331 & 6016,08 & 15157,25 & 705,331 \\
\hline 2 & Tegalwaru & 668,853 & 5977,08 & 15065,25 & 668,853 \\
\hline 3 & Ciampel & 251,461 & 4501,88 & 12505,25 & 251,461 \\
\hline 4 & Telukjambe Timur & 5670,113 & 1050,48 & 2867,25 & 1050,48 \\
\hline 5 & Telukjambe Barat & 49,026 & 3399,08 & 10617,25 & 49,026 \\
\hline 6 & Klari & 8309,94 & 2052,08 & 70,25 & 70,25 \\
\hline 7 & Cikampek & 1544,2 & 571,68 & 5295,25 & 571,68 \\
\hline 8 & Purwasari & 352,94 & 1166,68 & 6178,25 & 352,94 \\
\hline 9 & Tirtamulya & 21,026 & 3046,28 & 9876,25 & 21,026 \\
\hline 10 & Jatisari & 1821,983 & 444,68 & 3171,25 & 444,68 \\
\hline 11 & Banyusari & 241,505 & 1501,68 & 6844,25 & 241,505 \\
\hline 12 & Kotabaru & 2595,853 & 392,48 & 2351,25 & 392,48 \\
\hline 13 & Cilamaya Wetan & 53,287 & 2339,48 & 8663,25 & 53,287 \\
\hline 14 & Cimalaya Kulon & 168,244 & 1750,68 & 7419,25 & 168,244 \\
\hline 15 & Lemahabang & 132,722 & 1666,48 & 7483,25 & 132,722 \\
\hline 16 & Telagasari & 103,722 & 1889,08 & 7684,25 & 103,722 \\
\hline 17 & Majalaya & 33,113 & 3316,68 & 10446,25 & 33,113 \\
\hline 18 & Karawang Timur & 4660,679 & 272,28 & 1391,25 & 272,28 \\
\hline 19 & Karawang Barat & 10710,07 & 3026,28 & 70,25 & 70,25 \\
\hline 20 & Rawamerta & 135,722 & 1813,48 & 7489,25 & 135,722 \\
\hline 21 & Tempuran & 39,374 & 2261,08 & 8794,25 & 39,374 \\
\hline 22 & Kutawaluya & 71,244 & 2202,88 & 8657,25 & 71,244 \\
\hline 23 & Rengasdengklok & 620,635 & 830,88 & 5236,25 & 620,635 \\
\hline 24 & Jayakerta & 53,07 & 3440,48 & 10834,25 & 53,07 \\
\hline 25 & Pedes & 72,113 & 2049,28 & 8257,25 & 72,113 \\
\hline 26 & Cilebar & 165,287 & 4095,88 & 12062,25 & 165,287 \\
\hline 27 & Cibuaya & 36,026 & 3362,48 & 10581,25 & 36,026 \\
\hline 28 & Tirtajaya & 186,418 & 4234,68 & 12115,25 & 186,418 \\
\hline 29 & Batujaya & 101,94 & 3625,28 & 11170,25 & 101,94 \\
\hline 30 & Pakisjaya & 54,244 & 2237,08 & 8315,25 & 54,244 \\
\hline
\end{tabular}

Sumber: Hasil Penelitian (2021)

3) Pengelompokan data ke dalam cluster berdasarkan jarak terdekat, data yang mempunyai jarak terdekat akan masuk kedalam cluster tersebut dijelaskan pada tabel 5. Kabupaten Pangkalan dikelompokkan pada C1, Tegalwaru dikelompokkan pada C1, Ciampel dikelompokkan pada C1, Telukjamber Timur dikelompokkan pada C2, Telukjambe Barat dikelompokkan pada C1, Klari dikelompokkan pada C3, Cikampek dikelompokkan pada C2, Purwasari dikelompokkan pada C1, Tirtamulya dikelompokkan pada C1, Jatisari dikelompokkan pada C2, Banyusari dikelompokkan pada C1, Kotabari dikelompokkan pada C2, Cilamaya Wetan dikelompokkan pada C1, Cimalaya Kulon dikelompokkan pada C1, Lemahabang dikelompokkan pada C1, Tegalsari dikelompokkan pada C1, Majalaya dikelompokkan pada C1, Karawang Timur dikelompokkan pada C2, Karawang Barat dikelompokkan pada C3, Rawamerta dikelompokkan pada C1, Tempuran dikelompokkan pada C1, Kutawaluya dikelompokkan pada C1, Rengasdengklok dikelompokkan pada C1, Jayakarta dikelompokkan pada C1, Pedes dikelompokkan pada C1, Cilebar dikelompokkan pada C1, Cibuaya dikelompokkan pada C1, Tirtajaya dikelompokkan pada C1, Batujaya dikelompokkan pada C1 dan Pakisjaya dikelompokkan pada $\mathrm{C} 1$ yang dijelaskan pada tabel 5. 
Tabel 5. Pengelompokan Data Iterasi Kedua

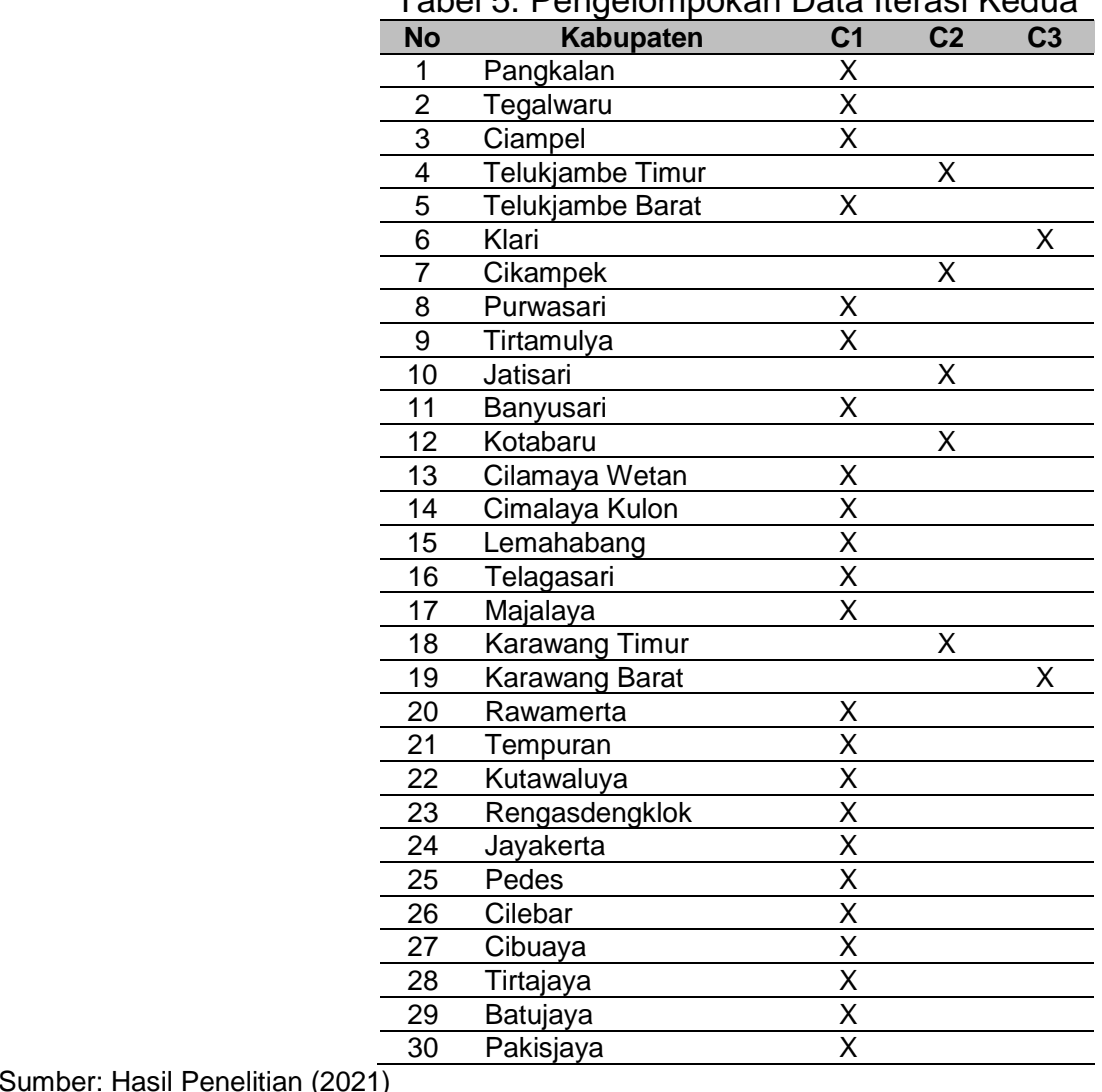

Sumber: Hasil Penelitian (2021)

Pada iterasi kedua hasil pengelompokan data sama dengan hasil pengelompokan iterasi pertama, maka proses pengolahan dataset berhenti sampai disini. Hasil pengolahan dari dataset didapatkan cluster 1 sebanyak 23 kecamatan, cluster 2 sebanyak 5 kecamatan dan cluster 3 sebanyak 2 kecamatan.

\section{K-Means}

Clustering memiliki konsep dimana Elemen data $\mathrm{K}$ dipilih sebagai center, kemudian jarak semua data elemen dihitung menggunakan rumus Euclidean. Elemen data yang memiliki jarak kurang ke centroid dipindahkan ke cluster yang sesuai. Proses dilanjutkan hingga tidak ada lagi perubahan yang terjadi dalam cluster [k-1] [14]. Metode ini merupakan metode pengelompokan nonhirarki yang bertujuan untuk mengelompokkan objek sehingga jarak-jarak tiap objek ke pusat kelompok di dalam satu kelompok bernilai minimum [13]. Data diproses dengan menggunakan algoritma k-means clustering. Adapun proses yang dilewati pada algoritma K-means adalah sebagai berikut: 1. Menentukan jumlah cluster yang akan digunakan. Penentuan cluster atau $\mathrm{K}$ merupakan hal pertama yang harus dilakukan pada algoritma KMeans, dimana nilai $\mathrm{K}$ merupakan bilangan bulat positif. untuk penelitian ini nilai $\mathrm{K}$ yang digunakan adalah cluster $\mathrm{K}=2$ sampai dengan $\mathrm{K}=10$. 2 . Kemudian menentukan centroid, penentuan centroid dilakukan dengan memberikan nilai secara acak pada tiap atribut 3 . Menghitung jarak setiap data dengan titik pusat setiap cluster centroid awal. Hal ini untuk mengetahui cluster mana yang paling dekat dengan data. 4. Menghitung kembali pusat cluster yang baru berdasarkan rata-rata angggota yang terdapat pada cluster tersebut setelah semua data ditempatkan ke dalam cluster yang terdekat, pada tahap ini iterasi terus dilakukan jika centroid belum konvergen dan iterasi hanya dapat dihentikan jika centroid yang baru bersifat konvergen dengan centroid yang lama. Pada penelitian ini, implementasi algoritma k-means menggunakan alat bantu/tools RapidMiner. Percobaan dilakukan pada data dengan menggunakan nilai $\mathrm{K}=2$ sampai dengan $\mathrm{K}=10$. Kemudian dievaluasi dengan menggunakan uji validasi clustering untuk mengidentifikasi cluster terbaik. 


\section{Implementasi K-Means dengan Rapidminer}

Pengolahan dataset fasilitas kesehatan di Kabupaten Karawang telah didapatkan, kemudian akan dilakukan pengolahan dataset kembali menggunakan Rapidminer sebagai bahan perbandingan. Hasil yang didapatkan berdasarkan Rapidminer.

\section{Cluster Model}

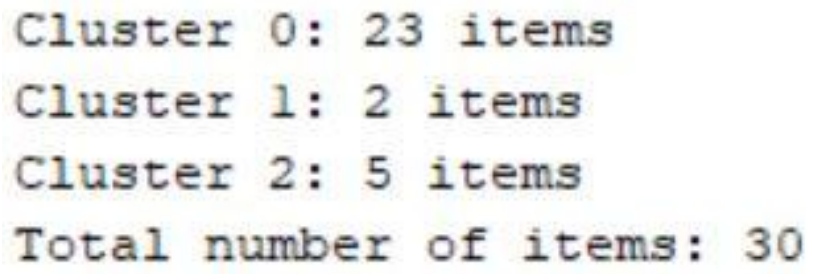

Sumber: Hasil Penelitian (2021)

Gambar 3. Hasil Cluster Algoritma K-Means

Gambar 3 menunjukkan hasil pengolahan data fasilitas kesehatan di Kabupaten Karawang dengan Algoritma K-Means yang terbagi menjadi 3 cluster yaitu cluster 0 sebanyak 23 kabupaten, cluster 1 sebanyak 2 kabupaten dan cluster 3 sebanyak 5 kabupaten yang dijelaskan pada gambar 3 .

\section{Analisa Hasil Pengolahan Data}

Clustering data fasilitas kesehatan di Kabupaten Karawang dengan algoritma K-Means yang menggunakan micorosoft excel maupun rapidminer menghasilkan pengelompokan yang sama pada setiap kelompoknya. Berdasarkan hasil pengolahan data didapatkan cluster 1 yang mempunyai fasilitas kesehatan sedikit sebanyak 23 kecamatan yaitu, Pangkalan, Tegalwaru, Ciampel, Telukjambe Barat, Purwasari, Tirtamulya, Banyusari, Cilamaya Wetan, Cilamaya Kulon, Lemahabang, Telagasari, Majalaya, Rawamerta, Tempuran, Kutawaluya, Rengasdengklok, Jayakerta, Pedes, Cilebar, Cibuaya, Tirtajaya, Batujaya, dan Pakisjaya. Cluster 2 yang mempunyai fasilitas kesehatan sedang sebanyak 5 kecamatan yaitu, Telukjambe Timur, Cikampek, Jatisari, Kotabaru Dan Karawang Timur. Cluster 3 yang mempunyai fasilitas kesehatan terbanyak terdapat 2 kecamatan yaitu, karawang barat dan klari. Parameter untuk mengukur kinerja algoritma K-Means dilakukan dengan menghitung Davies Bouldin Index dan Avg. within centroid distance. Davies Bouldin Index merupakan algoritma yang menghasilkan cluster dengan jarak inter-cluster rendah (kesamaan inter-cluster tinggi) dan jarak antar cluster tinggi (kemiripan antar cluster rendah) akan memiliki Davies-Bouldin Index yang rendah, algoritma cluster yang menghasilkan kumpulan cluster dengan indeks DaviesBouldin terkecil dianggap sebagai algoritma terbaik berdasarkan kriteria ini. Sedangkan Avg. within centroid distance merupakan rata-rata dalam jarak cluster dihitung dengan rata-rata jarak antara centroid dan semua contoh cluster. Gambar 4 menunjukkan hasil kinerja dari pengelompokan fasilitas kesehatan kabupaten karawang dengan nilai Davies Bouldin Index sebesar 0,109 dan Avg. within centroid distance sebesar 39,947.

\section{PerformanceVector}

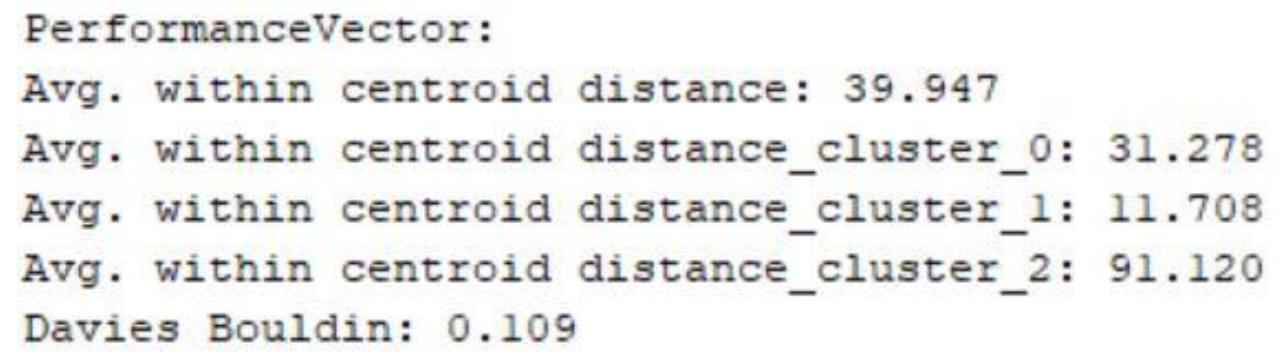

Sumber: Hasil Penelitian (2021)

Gambar 4. Hasil kinerja 
Perbandingan nilai Davies Bouldin Index berdasarkan jumlah cluster yang ditentukan. Dapat dilihat pada nilai Davies Bouldin Index dengan jumlah cluster 3, nilai yang dihasilkan bukan merupakan yang terbaik. Jumlah cluster terbaik berada pada jumlah k sebanyak 6 dengan Nilai Davies Bouldin Index sebesar 0,081. Untuk K pada Rumah Sakit=2, Puskesmas=3, Balai Kesehatan=4, Posyandu=5, Polindes=6, dan Apotek=7, dan DBI pada pada Rumah Sakit $=0,098$, Puskesmas $=0,109$, Balai Kesehatan $=0,111$, Posyandu $=0,107$ Polindes $=0,081$ dan Apotek=0,099.

\section{Kesimpulan}

Hasil pengolahan dataset fasilitas kesahatan yang ada di kabupaten karawang menghasilkan 3 cluster, yaitu cluster 1 dengan fasilitas kesehatan sedikit sebanyak 23 kecamatan, cluster 2 dengan fasilitas kesehatan sedang sebanyak 5 kecamatan dan cluster 3 dengan fasilitas kesehatan sebanyak 2 kecamatan. Ternyata masih banyak kecamatan yang mempunyai fasilitas kesehatan sedikit di karawang. Hal ini bisa dijadikan acuan bagi pemerintah dalam membangun fasilitas kesehatan agar masyarakat dapat berobat tanpa berpergian jauh dari tempat tinggal. Untuk penelitian lebih lanjut dapat melakukan pengoptimalan dengan teknik preprocessing data untuk menghasilkan hasil yang berkualitas dan menggunakan algoritma yang lain agar mendapatkan perbandingan.

\section{Referensi}

[1] Mayangsarim, Sekar D.S., Solikhun \& Irawan. Pengelompokkan Jumlah Desa/Kelurahan yang Memiliki Sarana Kesehatan menurut Provinsi dengan Menggunakan Metode KMeans Cluster. Konferensi Nasional Teknologi Informasi dan Komputer (KOMIK), vol. 3, pp. 370-377, 2019.

[2] Sadewo \& Gading M. Pemanfaatan Algoritma Clustering dalam Mengelompokkan Jumlah Desa/Kelurahan yang Memiliki Sarana Kesehatan Menurut Provinsi dengan K-Means. Konferensi Nasional Teknologi Informasi dan Komputer (KOMIK), vol. 1, pp. 124-131, 2017.

[3] Han, J., Kamber, M. \& Pei, J. Data mining: concepts and techniques Third Edition. Morgan Kaufmann Publishers, San Francisco, 2011.

[4] Hantoro, Kusdarnowo., Andi S. \& Siti A. Pencarian Lokasi Perumahan Berdekatan dengan Fasilitas Kesehatan dan Belanja menggunakan Algoritma K-Means. Jurnal IKRA-ITH Informatika, vol 4, pp.25-34, 2020.

[5] Silitonga, Parasian D.P \& Damanik R. Implementasi Algoritma K-Means Clustering pada Analisis Penyebaran Penynakit Pasien Pengguna Badan Penyelenggara Jaminan Sosial Kesehatan (BPS). Jurnal Teknik Informatika Unika St. Thomas (JTIUST), vol. 1, pp. 37-41, 2016.

[6] Supriyatna A., Carolina I., Widiati W. \& Nuraeni C. Rice Productivity Analysis by Province Using K-Means Cluster Algorithm. IOP Conf. Ser. Mater. Sci. Eng., vol. 771, p. 012025, 2020.

[7] Supriyatna A., Carolina I., Janti S., \& Haidir A. Clustering Koridor Transjakarta Berdasarkan Jumlah Penumpang Dengan Algoritma K-Means. Jurnal Sains Komputer \& Informatika (JSAKTI), vol. 4, pp. 682-693, 2020.

[8] R. Setiawan, "Penerapan Data Mining Menggunakan Algoritma K-Means Clustering untuk Menentukan Strategi Promosi Mahasiswa Baru (Studi Kasus: Politeknik LP3I Jakarta)," J. Lentera ICT, vol. 3, no. 1, pp. 76-92, 2016.

[9] Y. Mardi, "Data Mining: Klasifikasi Menggunakan Algoritma C4.5," J. Edik Inform., vol. 2, no. 2, pp. 213-219, 2017.

[10] A. F. Lestari and M. Hafiz, "Penerapan Algoritma Apriori Pada Data Penjualan Barbar Warehouse," J. INOVTEK Polbeng Seri Inform., vol. 5, no. 1, pp. 96-105, 2020.

[11] Mustofa Z, Suasana IS. Algoritma Clustering K-Medoids pada E-Government Bidang Information and Communication Technology Dalam Penentuan Status EDGI. Jurnal Teknologi Informasi dan Komunikasi, vol. 9, no. 1, pp. 1-10, 2018

[12] Jain Y K, Bhandare S K. Min Max Normalization Based Data Perturbation Method for Privacy Protection. International Journal of Computer \& Communication Technology (IJCCT), vol. 3, no. 4, pp. 45-50, 2014.

[13] Aditya KB, Diyah, Setiawan Y. Sistem Informasi Geografis Pemetaan Faktor-Faktor Yang Mempengaruhi Angka Kematian lbu (Aki) Dan Angka Kematian Bayi (AKB) Dengan 
Metode K-Means Clustering (Studi Kasus: Provinsi Bengkulu). Jurnal Teknik Informatika, vol. 10 , no. 1 , pp. 59-66, 2017

[14] Raval, UR. and Chaita J. Implementing \& Improvisation of K-means Clustering Algorithm. International Journal of Computer Science and Mobile Computing, vol.5 no.5, pp. 191-203, 2016. 